\title{
Organic Farming Improves Soil Microbial Abundance and Diversity under Greenhouse Condition: A Case Study in Shanghai (Eastern China)
}

\author{
Jianli Liao, Yun Liang and Danfeng Huang *(1) \\ Key Laboratory of Urban Agriculture (South), Ministry of Agriculture, School of Agriculture and Biology, \\ Shanghai Jiao Tong University, Shanghai 200240, China; Jerry0427@sjtu.edu.cn (J.L.); \\ yunliangdoreen@gmail.com (Y.L.) \\ * Correspondence: hdf@sjtu.edu.cn; Tel.: +86-21-3420-6943
}

Received: 13 September 2018; Accepted: 16 October 2018; Published: 22 October 2018

check for updates

\begin{abstract}
Agricultural practices have significant impacts on soil properties and microbial communities; however, little is known about their responses to open field and plastic tunnels under organic and conventional farming. We therefore investigated the responses of soil chemical variables and microbial communities to different agricultural management and cultivation types, including organic management in open field (OF), organic management in plastic tunnels (OP), conventional management in open field (CF) and conventional management in plastic tunnels (CP), by using a pyrosequencing approach of $16 \mathrm{~S}$ rRNA gene amplicon. Both factors had significant influences on the soil properties and microbial communities. Organic farming increased the nutrient-related soil variables compared to conventional farming regardless of cultivation type, especially for the available $\mathrm{N}$ and $\mathrm{P}$, which were increased by $137 \%$ and $711 \%$, respectively, in OP compared to $\mathrm{CP}$. Additionally, OP had the highest microbial abundance and diversity among treatments, whereas no difference was found between OF, CF and CP. Furthermore, OP possessed diverse differential bacteria which were mainly related to the organic material turnover (e.g., Roseiflexus, Planctomyces and Butyrivibrio) and plant growth promotion (e.g., Nostoc, Glycomyces and Bacillus). Redundancy analysis (RDA) showed that $\mathrm{pH}$, electrical conductivity (EC), nutrient levels (e.g., available $\mathrm{N}$ and available $\mathrm{P})$ and total $\mathrm{Zn}$ content were significantly correlated to the structure of the microbial community. Overall, our results showed that the long-term organic farming with high fertilizer input increased soil nutrient levels and microbial abundance and diversity under plastic-tunnel condition compared to other cultivation systems.
\end{abstract}

Keywords: organic farming; soil microbiota; agricultural practice; greenhouse; horticultural soil; soil properties

\section{Introduction}

Soil provides important functions in agroecosystems, such as organic material turnover, nutrient cycling and xenobiotics adsorption and degradation [1]. Microbes have been considered as the key drivers in these functions in the agroecosystem. Furthermore, a number of soil microbes could promote crop growth by producing antibiotics and plant hormones and increase nutrient availability (e.g., excrete phosphatase) and, as a consequence, benefit plant quality and productivity [2]. Recently, research on the soil microbial community and its function in the agricultural production system has received increasing attention. These investigations have identified that microbial attributes could reflect ecosystem processes such as crop productivity [3], the regulation of decomposition [4], nutrient cycling [5] and protection against soil-borne pathogens [6]. Several studies have shown that agricultural 
practices have significant influences on soil microbial communities and composition, including the tillage regime [7], fertilization [8], monoculture [9], crop residue management [10] and plant protection schemes [11]. Hence, the soil microbial community could be shifted to a positive organization for plant production and ecosystem sustainability by suitable agricultural practices [4].

With the benefits of the green revolution, the development and use of chemical fertilizer, agrochemicals and irrigation systems have significantly increased the efficiency of crop productivity worldwide [12]. In recent years, however, great soil degradation was observed, such as by soil erosion, salinization, acidification, pollution by heavy metals and xenobiotics, and an increased abundance of plant pathogens [4]. These adverse effects led to the reduction of productivity and were mainly due to unsuitable intensive agricultural practices such as repeated tillage and the overuse of synthetic fertilizer and agrochemicals [13]. To minimize these negative impacts, organic farming has been proposed as a sustainable agricultural practice with the main principles of the ecological cycle (e.g., the reuse of composted local organic materials and avoiding the use of agrochemicals) and biodiversity (e.g., rotation and biocontrol) when compared to conventional farming [14]. By the end of 2015, there were approximately 44 million hectares of land that were managed organically over the world. China was the third largest country in terms of its land area under organic management in the world (2.28 million hectares; the first two countries are Australia and Argentina), and the dedicated land area has been steadily growing in recent years [15].

Organic farming has been shown to increase environmental biodiversity in terms of animals, insects and butterflies when compared to conventional farming $[14,16]$. Several studies also suggested that microbial abundance [4] and diversity [9] were higher in soils under organic management than in soils under conventional practice. The increased microbial diversity could be related to reduced tillage [17], cover cropping [18] and organic fertilizer incorporation [19] by improving soil organic carbon as the energy source of heterotrophic microbiota [20]. Furthermore, high microbial diversity has been linked to high functional diversity in soil [5], which may cause the important ecological processes mentioned above. In addition, most researchers studied the microbial community under different agricultural management practices with field crops such as rice [3,21] and wheat [10], whereas little research has focused on vegetable cultivations [22]. Specifically, we still have a limited understanding of the long-term effects of organic and conventional management on soil microbial communities under open-field and protected conditions.

Protected cultivation methods, such as plastic (e.g., polyethylene) cover and greenhouses which mostly allowed sunlight to penetrate, were built to grow plants with a range of advantages, including early harvest and a high quantity, quality and off-season production [23]. In China, there were approximately 4 million hectares of protected vegetables in 2010, which account for over $80 \%$ of all protected vegetable production in the world [23]. There is an increasing concern, however, that this type of cultivation profoundly changes soil properties by regulating water and temperature. Drip and sprinkler irrigation as alternatives due to rainfall limitation under covered cultivation result in increased salinity accumulation on the soil surface by reducing soil leaching. Furthermore, optimal water and temperature control could enhance organic matter degradation in the soil, which leads to lower soil carbon content and results in negative effects on soil microbial communities [22]. In this regard, organic farming has been shown to improve soil carbon content and have a positive effect on soil microbial diversity, which may offset the negative effects of protected cultivation on soil quality and microbiota. However, the impacts of organic farming with protected cultivation on soil properties and the microbial community are not well understood.

In this context, we investigated the response of soil properties and the microbial community in soils under open-field and protected conditions managed organically and conventionally. We hypothesized that long-term organic farming shifted the soil microbial composition and improved soil organic matter turnover, specifically for soil under the plastic tunnel condition. To test this hypothesis, we used high-throughput sequencing of the $16 \mathrm{~S}$ rRNA gene markers to analyze microbial communities and measured a range of soil variables in open-field and plastic-tunnel soils under organic 
and conventional farming systems. The overall goal of this study was to get a better understanding of how cultivation management (organic vs. conventional) and type (open field vs. plastic tunnel) can affect the composition of the soil microbial community and the cultivation-associated microbiota in the corresponding cultivation system.

\section{Materials and Methods}

\subsection{Sites Description}

The study site is located in the urban area of Shanghai (Eastern China), which has a humid subtropical climate with a mean annual temperature of $17.5^{\circ} \mathrm{C}$ and rainfall amount of $\sim 1300 \mathrm{~mm}$. Four horticultural soils were selected: (1) organic practice in open field (OF); (2) organic practice in plastic tunnel (OP); (3) conventional practice in open field (CF) and (4) conventional practice in plastic tunnel (CP). The soils were clay loam and were classified as fluvisol according to the World Reference Base for Soil Resources [24]. The organic soils were sampled in the Horticultural Research Station of Shanghai Jiao Tong University, Shanghai, China (27 hectares, Organic Certification No. 134OP1200092), which was established in 2008, approximately $5 \mathrm{~km}$ from the East China Sea $\left(30^{\circ} 51^{\prime} \mathrm{N}, 121^{\circ} 5^{\prime} \mathrm{E}\right)$. The conventional farm was closed to the research station and has continuously produced vegetables for more than 10 years. The plastic tunnels in both organic and conventional farms have been set up and used for vegetable production for 7 years. The organic soils were fertilized with commercial organic fertilizer, which was produced from mushroom waste and chicken manure, N-P-K (2.3-4.5-2.6) with an organic matter content of $77.3 \%$ and total $\mathrm{Zn} 425 \mathrm{mg} \mathrm{kg}^{-1}$ at an average rate of 90 and 105 ton ha $^{-1}$ year $^{-1}$ for open-field and plastic-tunnel cultivation, respectively. A complex fertilizer N-P-K (15:15:15) was used at an average rate of 8 and 10 ton ha $^{-1}$ year ${ }^{-1}$ for conventional open-field and protected cultivation, respectively. Additionally, urea was used at an average rate of 0.2 ton ha $^{-1}$ year $^{-1}$ for both cultivation types in conventional management. Three and four crops are produced annually in the open fields and plastic tunnel, respectively. The dominant crops cultivated in rotation are onion (Allium cepa L.), sweet potato (Ipomoea batatas L.), green onion (Allium fistulosum L.), Chinese cabbage (Brassica rapa pekinensis), and pepper (Capsicum annuum L.) for open fields, while these were pakchoi (Brassica campestirs spp. chinensis Makino var. communis Tsen et Lee), celery (Apium graveolens var. dulce), cucumber (Cucumis sativus L.), alfalfa (Medicago sativa L.), spinach (Spinacia oleracea L.), lettuce (Lactuca sativa L.) for the plastic tunnel. Pests and diseases were controlled by cultural practices (e.g., rotation) and agricultural chemicals (e.g., mandipropamid, chlorpyrifos and spinosad) in organic and conventional plots, respectively. Weeds were removed manually in organic plots, while herbicides (e.g., glyphosate and linuron) were used in conventional management plots. Furrow irrigation was applied in open fields, while drip and sprinkler irrigations were used in the greenhouse condition to maintain the water content $(60-70 \%)$ for plant growth.

\subsection{Soil Collection}

To minimize soil variation by external disturbance, the soils at $10-20 \mathrm{~cm}$ depth were collected by 5.5-cm-diameter stainless steel auger after plant harvest in January 2016 . We selected an $8 \mathrm{~m} \times 40 \mathrm{~m}$ plot from each cultivation system and collected subsamples at regular $2.5 \mathrm{~m} \times 8 \mathrm{~m}$ intervals, $15 \mathrm{~cm}$ apart from the plant. In total, 15 samples were collected from each plot. After sampling, the soils were stored in polyethylene bags and kept on ice before being transferred to the lab. Three samples were randomly picked from the same cultivation system, mixed homogeneously and then passed through a sterilized 2-mm sieve as one replicate, resulting in five replicates per cultivation system. The sample was divided into three parts: one was stored at $4{ }^{\circ} \mathrm{C}$ and another was air-dried and passed through a 2-mm sieve for subsequence chemical analysis, while the other was stored at $-80^{\circ} \mathrm{C}$ prior to molecular analysis. 


\subsection{Soil Chemical Analysis}

The fresh soil was used for the determination of ammonium $\left(\mathrm{NH}_{4}{ }^{+}-\mathrm{N}\right)$ and nitrate $\left(\mathrm{NO}_{3}{ }^{-}-\mathrm{N}\right)$ after extraction with $2 \mathrm{M} \mathrm{KCl}(1: 10, w / v)$ using automated discrete analyzer (Smartchem, Frépillo, France). The air-dried soil was used for the following chemical properties: the soil $\mathrm{pH}$ and electrical conductivity (EC) was determined in a 1:5 $(w / v)$ soil/water slurry [25]. The cation exchangeable capacity (CEC) was measured by an ammonium acetate method. Soil-available $\mathrm{N}$ and available $\mathrm{P}$ were measured with the alkaline-hydrolyzable diffusion method [9] and Olsen method. A Vario El III elemental analyzer (Elementar, Langenselbold, Germany) was used to measure total soil C (Ctot) and total soil N (Ntot). The total amounts of $\mathrm{K}, \mathrm{Cu}$ and $\mathrm{Zn}$, which were shown as Ktot, Cutot and Zntot, respectively, were digested by aqua regia and measured using an inductively coupled plasma optical emission spectrometer (ICP-OES, Spectro Arcos, Ametek, Meerbusch, Germany).

\subsection{Soil Microbial Analysis}

The genomic DNA was extracted from approximately $0.5 \mathrm{~g}$ of soil (wet weight) using the E.Z.N.A. Soil DNA Kit (Omega Bio-Tek, Norcross, GA, USA); details are provided in the Supplementary Information S1. The quantity and quality of DNA extracts $(1 \mu \mathrm{L})$ were quantified using a NanoDrop 2000 fluorospectrometer (Thermo Fisher Scientific, Waltham, MA, USA). The 16S microbial primers 515F (5'-GTGCCAGCMGCCGCGG-3') and 907R (5'-CCGTCAATTCMTTTRAGTTT-3') were used for amplifying the $\sim 400 \mathrm{bp}$ V4-V5 regions of the 16S rRNA gene. Amplicons from each PCR sample were pooled to equal amounts and sequenced on an Illumina MiSeq sequencer (Illumina Inc., San Diego, CA, USA) with MiSeq Reagent Kit v3 at the Shanghai Personal Biotechnology Co., Ltd. (Shanghai, China). Raw sequencing files were deposited in the National Centre for Biotechnology Information Sequence Read Archive (SRA) with the accession number "SRP156388".

Sequences were processed with the quantitative insights into microbial ecology (QIIME) pipeline version 1.8.0 [26]. Briefly, low-quality reads were discarded with an average Phred score lower than 20, lengths of less than $150 \mathrm{bp}$, ambiguous $\mathrm{N}$ bases and mismatched primers. The fast length adjustment of short reads (FLASH) software (v1.2.7) was employed to assemble filtered paired-end reads [27]. The contigs were assigned to operational taxonomic units (OTUs) at 97\% similarity using UCLUST [28]. A representative sequence was picked from each out, and BLAST was applied to assign the taxonomic classification against the Greengenes database (Release 13.8) [29]. Only those OTUs accounting for more than $0.001 \%$ of all sequence data were used for subsequent analysis.

\subsection{Statistical Analysis}

We used both multivariate and univariate analyses to assess the overall effects of the management (i.e., organic and conventional) and cultivation type (i.e., open field and plastic tunnel) on soil properties and microbial communities. For the multiple statistical tests, normalized soil variables were used to examine the similarities between cultivation systems by unconstrained principal coordinates analysis (PCoA), relying on a Euclidean distance. This distance matrix was then used to estimate the significance of the management and cultivation type by a permutational multivariate analysis of variance (PERMANOVA). For the univariate analysis, significant differences among cultivation systems were determined using Duncan's new multiple range test $(p<0.05)$.

Alpha-diversity characteristics, including the rarefaction curve, Good's coverage, indices of richness (Chao1 and ACE, i.e., abundance-based coverage estimator) and diversity (Shannon), in each soil sample were calculated by QIIME. Significant differences between these measures were determined by Duncan test $(p<0.05)$. An unconstrained PCoA based on Bray-Curtis index values were used to compare the $\beta$-diversity microbial community. PERMANOVA was applied to this distance matrix to examine the significance levels of the management and cultivation types on soil microbial communities. A linear discriminate analysis (LDA) effect size (LEfSe, LDA score > 3.8) was conducted to explore the differential microbial populations between different cultivation systems [30] and then visualized by 
using the ggpubr package in $\mathrm{R}$ (3.4.1) at the phylum and genus levels. The differential genera generated from LEfSe analysis were further used for the Spearman correlation analysis with soil chemical properties $(p<0.01$, absolute value of $r>0.6)$. A redundancy analysis (RDA) was applied to examine the relationship between soil environmental factors and the microbial community composition.

An unconstrained PCoA was conducted in the R environment (3.4.1) by a vegan package, while the PERMANOVA of the treatment groups was performed using 999 permutations in PAST3 software [31]. Duncan analysis was carried out in SPSS (IBM, Chicago, IL, USA, version 22.0).

\section{Results}

\subsection{Soil Chemical Properties}

The edaphic variables of all four cultivation systems were clustered into groups, with $65.91 \%$ and $29.80 \%$ of the variance components explained by the first two axes (Figure 1a), which were separated based on cultivation type (i.e., open field and plastic tunnel) and agricultural management (i.e., organic and conventional practices), respectively. PERMANOVA analysis further indicated that cultivation type ( $p=0.001)$ was the main driver determining soil parameters while management $(p=0.025)$ was of subordinate importance (Table S1).
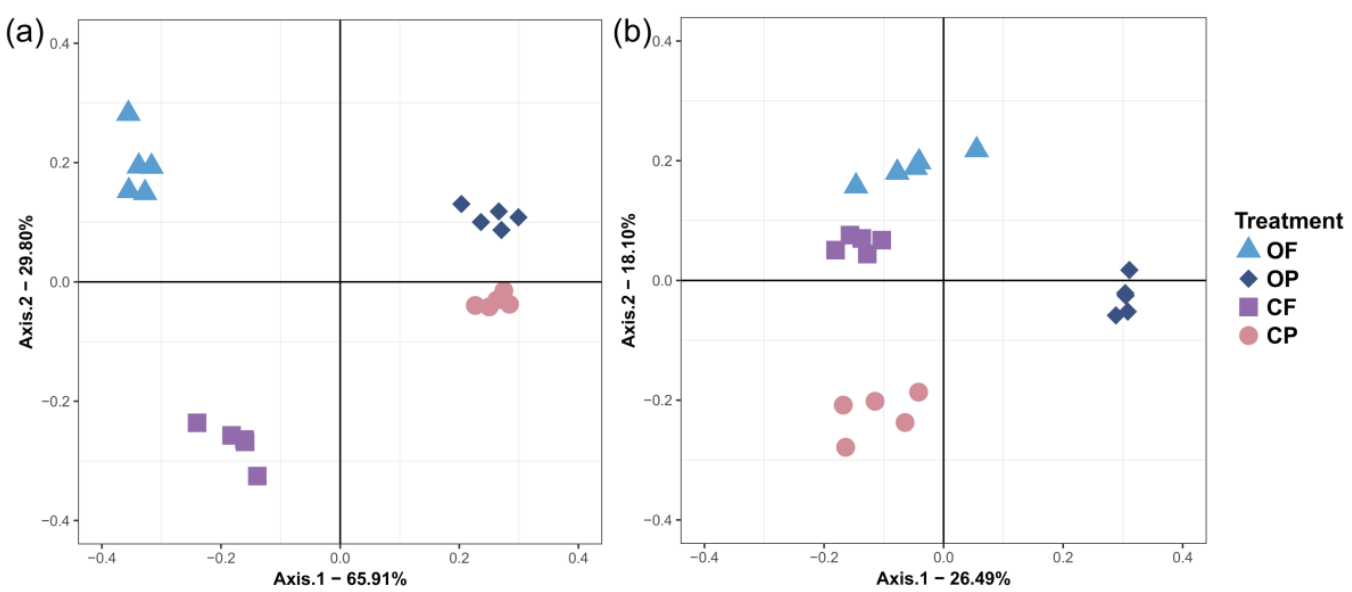

Figure 1. Unconstrained principal coordinates analysis (PCOA) illustrating the effect of fertilizers on (a) the Euclidean distances of soil properties, (b) the Bray-Curtis distance of microbial communities.

Univariate analysis showed that organic management had a pH of 7.32 and 7.28 in OF and OP, respectively, which were significantly lower than those in conventional management (7.59 and 7.83 in CF and CP, respectively, Table 1). The soil salinity in terms of EC was approximately twofold higher in OP $\left(0.34 \mathrm{dS} \mathrm{m}^{-1}\right)$ than the other treatments and decreased in the order $\mathrm{CP}>\mathrm{CF}>\mathrm{OF}$, while a similar trend was observed in available N. In addition, available P, Ctot, Ntot and Ktot $(\mathrm{OP}>\mathrm{OF}>\mathrm{CF}=\mathrm{CP})$ were significantly increased in soils under organic management compared to conventional management. The $\mathrm{C} / \mathrm{N}$ ratio was significantly higher in $\mathrm{CP}$ than $\mathrm{OP}$, whereas opposite trends were observed in $\mathrm{CEC}, \mathrm{NO}_{3}{ }^{-}-\mathrm{N}$, Cutot and Zntot. Soil $\mathrm{NH}_{4}{ }^{+}-\mathrm{N}$ showed the highest content in OF $\left(7.86 \mathrm{mg} \mathrm{kg}^{-1}\right)$, followed by OP $\left(7.42 \mathrm{mg} \mathrm{kg}^{-1}\right)$ and CP $\left(6.40 \mathrm{mg} \mathrm{kg}^{-1}\right)$, while CF had the lowest content (5.11 mg kg$\left.{ }^{-1}\right)$. In general, organic management, especially for the plastic tunnel, had higher nutrient content $\left(\mathrm{NH}_{4}{ }^{+}-\mathrm{N}, \mathrm{NO}_{3}{ }^{-}-\mathrm{N}\right.$, available $\mathrm{N}$, available $\mathrm{P}$ and $\left.\mathrm{Ntot}\right)$ and Zntot but lower values of soil $\mathrm{pH}$ and $\mathrm{C} / \mathrm{N}$ ratio than conventional management. 
Table 1. The soil chemical properties under different cultivation systems.

\begin{tabular}{|c|c|c|c|c|c|c|c|c|}
\hline Parameter & OF & & OP & & $\mathrm{CF}$ & & $\mathrm{CP}$ & \\
\hline $\mathrm{pH}$ & $7.32 \pm 0.03$ & c & $7.28 \pm 0.10$ & $\mathrm{c}$ & $7.59 \pm 0.26$ & $\mathrm{~b}$ & $7.83 \pm 0.13$ & a \\
\hline $\mathrm{EC}\left(\mathrm{dS} \mathrm{m}^{-1}\right)$ & $0.14 \pm 0.01$ & $\mathrm{~d}$ & $0.34 \pm 0.01$ & $\mathrm{a}$ & $0.17 \pm 0.01$ & c & $0.19 \pm 0.02$ & 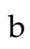 \\
\hline Available $\mathrm{N}\left(\mathrm{mg} \mathrm{kg}^{-1}\right)$ & $114.6 \pm 14.3$ & $\mathrm{c}$ & $2099 \pm 410$ & $\mathrm{a}$ & $106.1 \pm 8.92$ & $\mathrm{c}$ & $883.8 \pm 31.2$ & $b$ \\
\hline Available P $\left(\mathrm{mg} \mathrm{kg}^{-1}\right)$ & $181.7 \pm 58.1$ & $\mathrm{~b}$ & $247.6 \pm 32.0$ & a & $9.40 \pm 4.63$ & c & $30.5 \pm 4.63$ & c \\
\hline Ctot $(\%)$ & $1.93 \pm 0.40$ & $\mathrm{~b}$ & $2.83 \pm 0.45$ & $\mathrm{a}$ & $1.33 \pm 0.16$ & c & $1.24 \pm 0.04$ & c \\
\hline Ntot (\%) & $0.19 \pm 0.05$ & $\mathrm{~b}$ & $0.29 \pm 0.04$ & $\mathrm{a}$ & $0.13 \pm 0.01$ & c & $0.12 \pm 0.01$ & C \\
\hline Ktot $(\%)$ & $2.06 \pm 0.30$ & $\mathrm{ab}$ & $2.28 \pm 0.16$ & $\mathrm{a}$ & $1.89 \pm 0.16$ & $\mathrm{~b}$ & $1.21 \pm 0.12$ & c \\
\hline $\mathrm{C} / \mathrm{N}$ & $10.0 \pm 0.50$ & $\mathrm{~b}$ & $9.74 \pm 0.24$ & $\mathrm{~b}$ & $10.1 \pm 0.57$ & $a b$ & $10.5 \pm 0.47$ & $\mathrm{a}$ \\
\hline $\mathrm{CEC}\left(\mathrm{cmol}_{(+)} \mathrm{kg}^{-1}\right)$ & $13.2 \pm 0.91$ & $\mathrm{~b}$ & $17.9 \pm 1.41$ & $\mathrm{a}$ & $12.2 \pm 0.99$ & $\mathrm{~b}$ & $9.58 \pm 0.50$ & $c$ \\
\hline $\mathrm{NO}_{3}{ }^{-}-\mathrm{N}\left(\mathrm{mg} \mathrm{kg}^{-1}\right)$ & $2.67 \pm 2.07$ & $\mathrm{c}$ & $46.4 \pm 4.42$ & $\mathrm{a}$ & $18.2 \pm 13.1$ & $\mathrm{~b}$ & $3.36 \pm 2.20$ & c \\
\hline $\mathrm{NH}_{4}^{+}-\mathrm{N}\left(\mathrm{mg} \mathrm{kg}^{-1}\right)$ & $7.86 \pm 0.97$ & $\mathrm{a}$ & $7.42 \pm 1.08$ & $a b$ & $5.11 \pm 0.47$ & c & $6.40 \pm 1.08$ & $\mathcal{N}$ \\
\hline Cutot $\left(\mathrm{mg} \mathrm{kg}^{-1}\right)$ & $17.5 \pm 1.74$ & $a b$ & $23.2 \pm 1.31$ & $\mathrm{a}$ & $20.0 \pm 7.94$ & $\mathrm{ab}$ & $16.1 \pm 1.15$ & $\mathrm{~b}$ \\
\hline Zntot $\left(\mathrm{mg} \mathrm{kg}^{-1}\right)$ & $129.5 \pm 13.3$ & $a b$ & $156.7 \pm 3.08$ & $\mathrm{a}$ & $120.1 \pm 31.1$ & $\mathrm{~b}$ & $123.0 \pm 22.1$ & $\mathrm{~b}$ \\
\hline
\end{tabular}

Different letters indicate statistically significant differences $(p<0.05)$ according to Duncan's test $(\mathrm{n}=5)$. OF: organic management in open fields; OP: organic management in plastic tunnels; CF: conventional management in open fields; $\mathrm{CP}$ : conventional management in plastic tunnels; EC: electrical conductivity; $\mathrm{CEC}$ : cation exchangeable capacity.

\subsection{Microbial $\alpha$-and $\beta$-Diversity}

A total of $812,526(40,276 \pm 10,768$ per sample) $16 \mathrm{~S}$ sequences were obtained from the 20 samples covering five replicates for each of the four cultivation systems, which clustered into 7091 OTUs with the number of OTUs ranging from 5074 to 5657 per sample (Table 2). Rarefaction curves showed that the sampling effort was close to the plateau for all treatments, with Good's coverage values ranging between 0.89 and 0.93 (Figure S1 and Table 2), indicating that this processed dataset was sufficient for subsequent analysis.

Table 2. Richness estimators and diversity index for different cultivation systems at a $97 \%$ identify threshold.

\begin{tabular}{ccccccc}
\hline Cultivation System & Reads & OTUs & Coverage & ACE & Chao 1 & Shannon \\
\hline OF & 41,616 & 5380 & 0.93 & $2227 \pm 604.3 \mathrm{ab}$ & $1439 \pm 204.0 \mathrm{ab}$ & $9.10 \pm 0.19 \mathrm{~b}$ \\
OP & 48,983 & 5657 & 0.90 & $2738 \pm 563.4 \mathrm{a}$ & $1640 \pm 169.9 \mathrm{a}$ & $9.43 \pm 0.13 \mathrm{a}$ \\
CF & 36,064 & 5161 & 0.89 & $1866 \pm 92.50 \mathrm{~b}$ & $1343 \pm 85.83 \mathrm{~b}$ & $9.09 \pm 0.08 \mathrm{~b}$ \\
CP & 35,842 & 5047 & 0.89 & $1810 \pm 196.9 \mathrm{~b}$ & $1332 \pm 144.0 \mathrm{~b}$ & $9.18 \pm 0.17 \mathrm{~b}$ \\
\hline
\end{tabular}

Different letters indicate statistically significant differences $(p<0.05)$ according to Duncan's test $(\mathrm{n}=5)$. OTUs: operational taxonomic units; ACE: abundance-based coverage estimator.

Unconstrained PCoA indicated that the composition of microbial communities was clustered clearly under different cultivation systems, while a strong effect of OP was found on the first axis (Figure 1b). PERMANOVA further suggested that management $(p=0.001)$ and cultivation types $(p=0.002)$ significantly influenced microbial $\beta$-diversity (Table S1). Moreover, the microbial abundances estimated by ACE and Chao 1 indices were higher in OP than those in conventional management (Table 2). However, no clear difference of microbial abundance was observed between the open field and plastic tunnel under the same agricultural management. In addition, the microbial diversity represented by the Shannon index was significantly higher in OP than in the other cultivation systems.

To get a better understanding of the microbial community composition under these four cultivation systems, we first conducted microbial analysis at the phylum level. The result of pyrosequencing obtained 40 bacterial phyla and three archaea phyla across all soil samples. The three most dominant phyla under different soils were Proteobacteria (32.6\% in average), Chloroflexi (12\%) and Planctomycetes $(9.3 \%)$, which account for more than $50 \%$ of the total (Figure 2). 


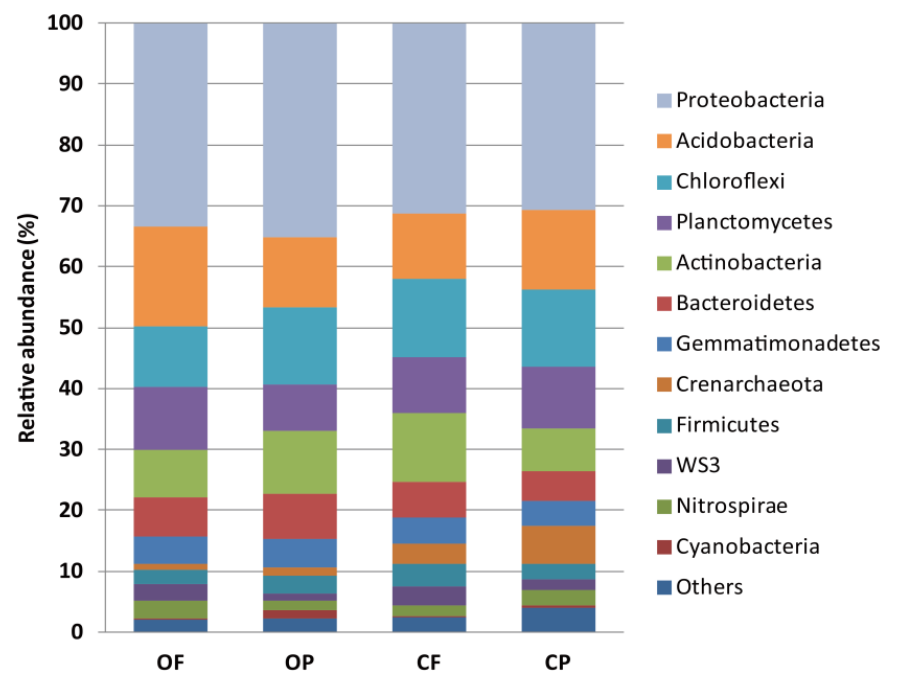

Figure 2. Relative abundance of dominant microbial phyla under different cultivation systems.

\subsection{Cultivation System-Associated Microbial Taxa}

We further applied LEfSe analysis to explore the potential distinct microbial communities under respective cultivation systems (Figure 3). The results indicated that OP enriched the most potential differential bacterial lineages in these environments. The relative abundances of the OTUs from phyla Planctomycetes and Cyanobacteria were significantly increased in OP. At the genus level, Roseiflexus (Chloroflexi) was the most differential taxon in OP (LDA score $=4.52$ ), followed by Planctomyces (Planctomycetes), Butyrivibrio (Firmicutes), Leptolyngbya (Cyanobacteria), Nostoc (Cyanobacteria), Glycomyces (Actinobacteria), Bacillus (Firmicutes), Microbulbifer (Proteobacteria), Pseudoxanthomonas (Proteobacteria) and Methylocaldum (Proteobacteria). In addition, the relative abundances of the genera Rhodoplanes (Proteobacteria) and Skermanella (Proteobacteria) were significantly enriched in OF and CF, respectively. Notably, the preferential taxa in $\mathrm{CP}$ were the Archaeal phylum Crenarchaeota and the genus Candidatus Nitrososphaera (Crenarchaeota).

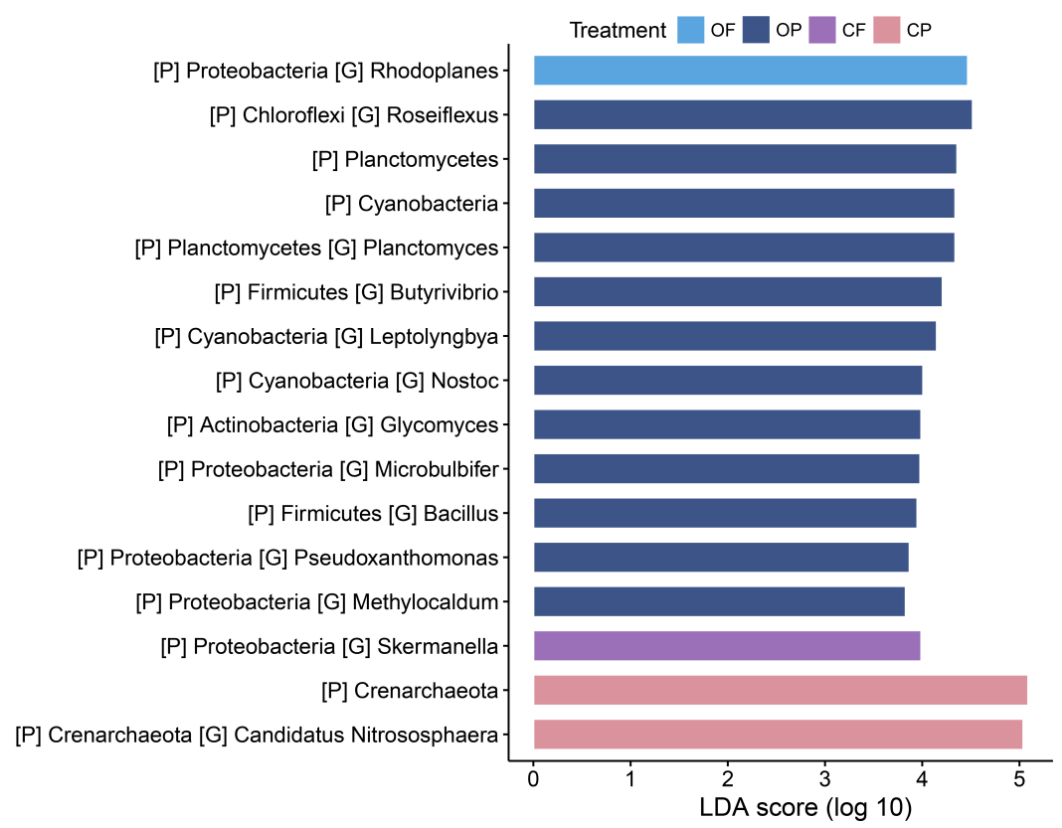

Figure 3. Comparison of microbial variations using the linear discriminate analysis (LDA) of effect size (LEfSe) online tool, with a histogram of the LDA scores for differential phyla and genera among groups. The threshold on the logarithmic LDA score for discriminative features was set to 3.8. 


\subsection{Relationships between the Microbial Community and Edaphic Properties}

RDA and Spearman correlation analyses were used to reveal how microbial communities are related to edaphic properties or may participate in the fundamental nutrient processes. The results of the RDA analysis showed that soil EC, CEC, available N, available P, Ctot and Ntot were the main factors which were highly associated to the soil microbial community in these studied sites $(p=0.001$, Figure 4, Table S2). In addition, significant correlations were also observed for soil $\mathrm{pH}, \mathrm{NO}_{3}{ }^{-}-\mathrm{N}$ and Zntot content $(p=0.005, p=0.008$ and $p=0.043$, respectively). Under the genus level, the correlations between differential genera and soil properties are shown in Table $3\left(\mathrm{C} / \mathrm{N}\right.$ ratio, $\mathrm{NH}_{4}{ }^{+}-\mathrm{N}$ and Zntot had no significant correlations with any genus). Soil $\mathrm{pH}$ was positively correlated to OTUs belonging to Candidatus Nitrososphaera and negatively correlated to OTUs belonging to Rhodoplanes. The genera associated with conventional management (i.e., Skermanella and Candidatus Nitrosophaera for open field and plastic tunnel, respectively) were negatively correlated to most of the nutrient-related properties. In contrast, all taxa that positively correlated with the nutrient-related variables and Cutot were highly associated with organic management. These genera were preferentially found in plastic tunnel soils, except for the genus Rhodoplanes.

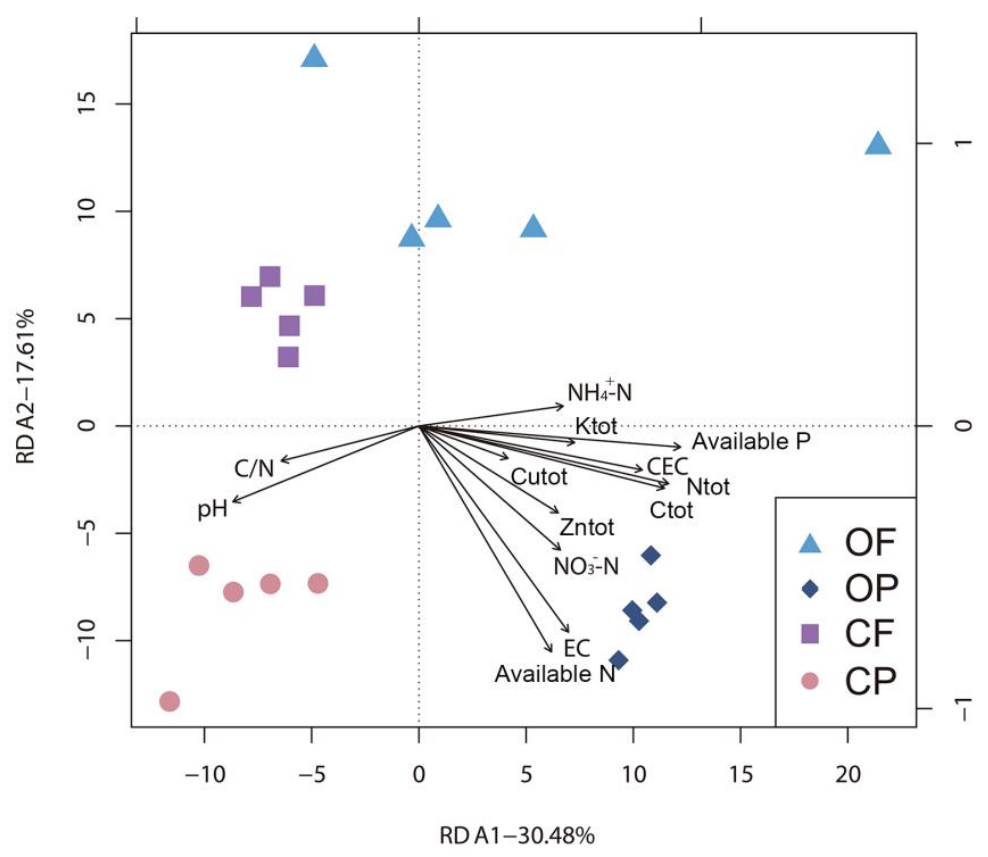

Figure 4. Redundancy analysis (RDA) of soil characteristics and microbial communities for individual samples. 
Table 3. Spearman correlation analysis between edaphic properties and differential genera of four cultivation systems.

\begin{tabular}{|c|c|c|c|c|c|c|c|c|c|c|c|}
\hline Treatment & Genus & $\mathrm{pH}$ & EC & Available N & Available P & Ctot & Ntot & Ktot & CEC & $\mathrm{NO}_{3}{ }^{-}-\mathrm{N}$ & Cutot \\
\hline $\mathrm{CF}$ & Skermanella & 0.12 & $-0.68^{* *}$ & $-0.90 * *$ & $-0.69 * *$ & -0.43 & -0.41 & -0.27 & -0.38 & -0.34 & -0.31 \\
\hline $\mathrm{CP}$ & $\begin{array}{c}\text { Candidatus } \\
\text { Nitrososphaera }\end{array}$ & $0.66^{* *}$ & 0.02 & -0.28 & $-0.74 * *$ & $-0.81 * *$ & $-0.86^{* *}$ & $-0.84^{* *}$ & $-0.85^{* *}$ & -0.33 & -0.60 \\
\hline OF & Rhodoplanes & $-0.64 * *$ & -0.34 & -0.10 & 0.57 & $0.71 * *$ & $0.72^{* *}$ & $0.62^{* *}$ & $0.66^{* *}$ & 0.04 & 0.30 \\
\hline \multirow{10}{*}{ OP } & Roseiflexus & -0.49 & $0.76^{* *}$ & $0.75^{* *}$ & $0.65^{* *}$ & $0.69 * *$ & $0.70^{* *}$ & 0.48 & $0.73^{* *}$ & $0.75^{* *}$ & 0.64 ** \\
\hline & Pseudoxanthomonas & -0.06 & $0.62 * *$ & $0.71^{* *}$ & 0.54 & 0.57 & 0.49 & 0.54 & 0.46 & 0.45 & 0.45 \\
\hline & Butyrivibrio & -0.57 & 0.59 & 0.60 & $0.67^{* *}$ & $0.72 * *$ & $0.74^{* *}$ & 0.48 & $0.74^{* *}$ & $0.61^{* *}$ & $0.62 * *$ \\
\hline & Leptolyngbya & -0.44 & $0.67 * *$ & $0.71^{* *}$ & $0.64^{* *}$ & 0.47 & 0.53 & 0.37 & 0.55 & 0.36 & 0.46 \\
\hline & Nostoc & -0.23 & $0.74^{* *}$ & $0.64^{* *}$ & 0.43 & 0.51 & 0.50 & $0.69^{* *}$ & 0.58 & $0.82 * *$ & 0.54 \\
\hline & Glycomyces & -0.35 & 0.56 & 0.54 & 0.43 & 0.59 & 0.56 & 0.33 & 0.58 & 0.53 & $0.61 * *$ \\
\hline & Microbulbifer & -0.12 & $0.69 * *$ & $0.88^{* *}$ & $0.60 * *$ & 0.50 & 0.42 & 0.51 & 0.46 & 0.47 & 0.49 \\
\hline & Bacillus & -0.16 & 0.58 & 0.53 & 0.44 & $0.62 * *$ & 0.53 & 0.32 & 0.49 & 0.58 & 0.49 \\
\hline & Planctomyces & -0.05 & $0.67 * *$ & $0.86^{* *}$ & 0.57 & 0.45 & 0.36 & 0.41 & 0.30 & 0.35 & 0.33 \\
\hline & Methylocaldum & -0.58 & 0.49 & 0.54 & $0.68^{* *}$ & $0.64 * *$ & $0.70^{* *}$ & $0.64 * *$ & $0.72 * *$ & 0.45 & 0.64 ** \\
\hline
\end{tabular}

Significant correlation was showed in bold. Significance levels: **: $p<0.01$. 


\section{Discussion}

In this study, we assessed the soil chemical properties and microbial communities in horticultural soils under different management (organic and conventional farming) and cultivation types (open field and plastic tunnel conditions). Overall, our results showed that edaphic variables and the microbial community structure were significantly influenced by management and cultivation type (Figure 1 and Table S1). We further explored the differential microbial taxa that may possess important ecological functions in corresponding cultivation systems (Figures 3 and 4). Moreover, the shifted soil properties under different cultivation systems had strong correlations with the microbial communities in these horticultural soils (Figure 4).

\subsection{Agricultural Management Affects Soil Properties}

Most of the studies to date have suggested that organic farming systems increase soil $\mathrm{pH}$ when compared to conventional farming in acidic soils by buffering from bicarbonates and organic acids in manure [32], while chemical fertilizer addition decreased soil acidity by acidification and nitrification [21]. However, opposite trends were observed here in a moderate alkaline soil in both open-field and plastic-tunnel cultivations. This observation was consistent with our previous study in the same county, which reported that the difference of $\mathrm{pH}$ was related to soil microbial activity under different management types [33]. In addition, the available $\mathrm{N}$, available $\mathrm{P}, \mathrm{Ntot}, \mathrm{Ktot}, \mathrm{CEC}$ and $\mathrm{NO}_{3}{ }^{-}-\mathrm{N}$ were significantly higher in soils managed organically than conventional practices, suggesting that organic farming could provide higher soil nutrient contents and nutrient capacity, potentially through long-term practice. Furthermore, the soil nutrient-related variables also reflected the over-use of fertilizers in both organic and conventional farming systems, especially for those soils under plastic tunnel conditions. For example, the available $\mathrm{N}$ in OP and CP was $2099 \mathrm{mg} \mathrm{kg}^{-1}$ and $883.8 \mathrm{mg} \mathrm{kg}^{-1}$, respectively, which was belonged to the extremely high level of soil available $\mathrm{N}\left(>150 \mathrm{mg} \mathrm{kg}^{-1}\right)$ according to the national soil survey in China [34]. Similarly, the available P in OP and CP belonged to the extremely high level $\left(>40 \mathrm{mg} \mathrm{kg}^{-1}\right)$ and high level $\left(20-40 \mathrm{mg} \mathrm{kg}^{-1}\right)$, respectively. Notably, the $\mathrm{Zn}$ content in the studied soils was between the background level $\left(100 \mathrm{mg} \mathrm{Zn} \mathrm{kg}^{-1}\right)$ and regulatory standard (300 mg Zn kg-1) in China [35]. The highest $\mathrm{Zn}$ content in soil was observed in OP, which was introduced by organic fertilizer with high $\mathrm{Zn}$ content $\left(425 \mathrm{mg} \mathrm{kg}^{-1}\right)$. Although organic farming could improve soil quality, it should be noted that inappropriate application of organic fertilizer might cause potential risks for food safety (e.g., Zn accumulation in plants) and environmental quality (e.g., soil salinity and eutrophication) under long-term use. In addition, the over-use of chemical fertilizer also has negative effects on the environmental quality. To avoid these issues, soil testing has been promoted by the Ministry of Agriculture to determine the application rate of fertilizers and the introduced "action plan for zero increase of fertilizer use in 2020" in 2015 aims to protect the soil quality and increase the effectiveness of fertilizer utilization in China [36].

Plastic-tunnel production provides a physical protection to prevent pests and rainfall from plants and results in a higher rate of evaporation caused by the greenhouse effect than open fields. This phenomenon could be found in our study in terms of the higher salinity (i.e., EC) and nutrient levels in plastic tunnels under both organic and conventional managements. Meanwhile, the optimal temperature in covering cultivation could enhance organic matter degradation in plastic-tunnel production [22], as could be observed from the fact that Ctot in $\mathrm{CP}$ was $6.8 \%$ lower than in the $\mathrm{CF}$ plot. However, organic farming increased Ctot in both open-field and plastic-tunnel conditions, which could lead to lower bulk density and well aggregated soil in these soils and thus provide better soil conditions for plant growth.

\subsection{Soil Microbial Community Shifted by Cultivation Systems}

The cultivation histories were different in these cultivation systems, implying that the difference of crops could be a factor to alert soil microbial communities by plant root exudates and/or residues. 
However, this possibility was minimized by sampling bulk soil $(10-20 \mathrm{~cm})$, and the sampling site was $15 \mathrm{~cm}$ away from the plant. In addition, a previous study has suggested that soil properties play predominant roles in shaping the soil bacterial community rather than the influence of crops [37]. In this regard, the effects of agricultural practices (e.g., fertilization) on edaphic properties are stronger than the effects of crops. Thus, we suppose that the shifted soil properties caused by agricultural practices could have a greater influence on the microbial community in soil than the effect of different cultivation histories in these agricultural practices. Additionally, the microbial abundance and diversity in OP were significantly higher than conventional management (i.e., $\mathrm{CF}$ and $\mathrm{CP}$ ). This indicated that plastic-tunnel cultivation could potentially enlarge the effect of organic farming practice on the microbial community, which might be related to the sufficient $C$ supply and the optimal temperature and water conditions [38] when compared to the open-field condition. Thus, organic farming increased the microbial richness and diversity in soils, leading to a more stable composition of the bacterial community under the organic plastic-tunnel condition. However, it should be noted that the studied sites were over-fertilized and the nutrient levels were extremely high in OP. In this regard, this studied soil might not be sustainable. Therefore, the effects of an appropriate lower input of organic farming system on the soil bacterial community should be investigated to get a better understanding of how the microbial community would change under sustainable agricultural practices. Meanwhile, no difference was found between these two cultivation types under conventional farming, which might be related to the use of agricultural chemicals (e.g., pesticides and fungicide) that result in a harmful environment for microbial propagation.

\subsection{Differential Taxa for Cultivation Systems}

LEfSe analysis showed that the phyla Planctomycetes and Cyanobacteria were the preferential bacterial communities in OP soil. Members belonging to Planctomycetes have been reported as major groups to decompose heteropolysaccharide [39] and chitin [40] and are involved in the C cycle in soils, which might be related to the highest Ctot content being in OP soil. OTUs from Cyanobacteria are photoautotrophs and play key roles in biogeochemical processes in nature and improve the turnover of $\mathrm{C}$ and $\mathrm{N}$ in the soil [41]. In addition, we also observed that the archaeal phylum Crenarchaeota was significantly increased in CP. OTUs belonging to this phylum have been shown to play important role in the $\mathrm{N}$ cycle as ammonia oxidizers [21]. However, it is difficult to define their functions at the phylum level, and we thus further considered them at the lower classification [10].

Among the genus levels, a total of 13 treatment-associated genera were found. Among the 10 genera that were enriched in OP, most of them have different signatures related to plant growth promotion and organic material turnover. For example, OTUs of the genera Nostoc (Cyanobacteria), Pseudoxanthomonas (Proteobacteria), Glycomyces (Actinobacteria), Leptolyngbya (Cyanobacteria) and Bacillus (Firmicutes) have been reported as beneficial bacteria. Specifically, Nostoc spp. and Pseudoxanthomonas spp. have been shown as N fixers [41,42]. OTUs within the genera Glycomyces and Leptolyngbya could inhibit other pathogens by producing antibiotics (e.g., streptomycin) [43,44]. Bacillus spp. are known as versatile plant growth-promoting bacteria (PGPB) by producing plant hormones (e.g., auxin), antibiotics (e.g., surfactin) and/or phosphatase [2]. This was in line with our previous study, which indicated that organic fertilizer addition could increase the abundance of PGPB and improve the nutrient processes in the soil [45]. In addition, the genera Roseiflexus (Chloroflexi), Planctomyces (Planctomycetes), Butyrivibrio (Firmicutes), Microbulbifer (Proteobacteria) and Methylocaldum (Proteobacteria) have been shown to be involved in organic substance degradation in soil. Roseiflexus spp., Planctomyces spp. and Butyrivibrio spp. are able to degrade organic substances such as cellulose, hemicelluloses or chitin [46-48]. Microbulbifer spp. belong to the aerobic sulfate-reducing bacteria, which have been shown to be dominant carbohydrate degraders in sandy sediments [49]. OTUs assigned to Methylocaldum have been reported to possess the pmoA gene involved in methane oxidation [50]. We also found positive correlations between these organic substance degraders and nutrient-related soil variables (Table 3), indicating that the increased abundance of 
these taxa could potentially improve nutrient availability in the organic protected soil environment. Altogether organic plastic-tunnel soil possessed a versatile differential bacterial species, which may change the soil functions to improve plant fitness and nutrient availability.

The OF soil was significantly enriched the genus of Rhodoplanes (Proteobacteria). Most members of Rhodoplanes initiate the process of denitrification, which could reduce $\mathrm{NO}_{3}{ }^{-}-\mathrm{N}$ to $\mathrm{NO}$ or $\mathrm{N}_{2} \mathrm{O}$ and result in N loss [51]. In addition, the relative abundance of Candidatus Nitrososphaera (Crenarchaeota belonged to Archaea) and Skermanella (Proteobacteria) were significantly increased in CP and CF, respectively. Candidatus Nitrososphaera spp. was the only differential genus belonging to the ammonia-oxidizer Archaea (AOA) in this study and able to oxidize $\mathrm{NH}_{4}{ }^{-}-\mathrm{N}$ to $\mathrm{NO}_{3}{ }^{-}-\mathrm{N}$, which plays an important role in the $\mathrm{N}$ cycle in the environment [52]. This was in line with previous studies, which showed that the abundance of AOA was higher in chemical fertilizer-amended soil than that of organic fertilizer [53]. Members belonging to Skermanella are aerobic bacteria and have been isolated from the oligotrophic environment (e.g., desert and coal mine soil) [54,55], which were negatively correlated to nutrient-related soil properties (i.e., EC, available $\mathrm{N}$ and available $\mathrm{P}$, Table 3). It has been shown that the relative abundance of Skermanella was higher in conventional farming than organic practice under open-field conditions in Canada [56]. Consistently, another study in Mexico indicated that Skermanella could be regarded as the bioindicator for conventional open-field soil [10]. This observation implied that a distinct microbial community response to different cultivation systems could be used as a potential bioindicator for evaluating soil condition as soil microbes were the first responders to the changed soil environment.

\subsection{Relationships between Soil Properties and Microbial Communities}

Given that microbiota have a strong relationship with the soil environment, the shifted environmental factors could reshape the composition of the soil microbial community [9]. Here, RDA analysis showed that different cultivation practices alerted microbial communities in response to the changed soil chemical measurements. Consistent with the previous study, we found that $\mathrm{pH}$ had a significant influence on the soil microbial community structure, which was the well-known predictor of the microbial community in soils [11]. Interestingly, nutrient-related properties, except for inorganic $\mathrm{N}$ content and Ktot, had a higher significant level than $\mathrm{pH}$ (Table S2). This phenomenon might be due to the lower $\mathrm{pH}$ variation in such small-scale assessment. Therefore, we speculated that the shifted microbial community was mainly caused by the changed nutrient content, especially for the accelerated accumulation of salinity and nutrients under the plastic-tunnel condition when compared to open field (Figure 1b). Notably, despite the $\mathrm{Zn}$ content in the soil being lower than the regulatory standard in China ( $300 \mathrm{mg} \mathrm{kg}^{-1}$ when soil $\mathrm{pH}>7.5$ ), we observed a significant relationship with the composition of the microbial community, which agreed with previous studies in rice fields [57]. Thus, the potential risk of increased $\mathrm{Zn}$ content in soil should be noted in terms of the soil quality and microbial community structure. Further study is needed to focus on the responses of the soil microbial community to the heavy metal content introduced by such organic fertilizer.

\section{Conclusions}

In this study, we highlight the impacts of agricultural management and cultivation type with high fertilizer input on soil chemical properties and microbial communities. The results showed that organic management significantly improved soil nutrient levels and increased microbial abundance and diversity, especially in the plastic tunnel, when compared to conventional farming. Differential microbial taxa analysis suggested that organic plastic tunnel cultivation-enriched diverse bacterial linkages related to plant growth promotion and organic material turnover were positively correlated to a range of soil nutrient parameters. Furthermore, the microbial community composition was significantly correlated to the soil environment, such as $\mathrm{pH}, \mathrm{EC}$, Zntot and nutrient-related properties (i.e., available $\mathrm{N}$, available $\mathrm{P}, \mathrm{Ctot}, \mathrm{Ntot}, \mathrm{CEC}, \mathrm{NO}_{3}{ }^{-}-\mathrm{N}$ ). Our findings indicated that organic farming improved the soil carbon and nutrient content, microbial abundance and diversity, and the abundance 
of beneficial microorganisms. However, it should be concerned that the inappropriate application of organic fertilizer containing heavy metals (e.g., $\mathrm{Zn}$ ) should have more attention paid to it. The excess nutrients and $\mathrm{Zn}$ content may negatively affect the soil environmental health and the microbial community in terms of their sustainable agricultural development.

Supplementary Materials: The following are available online at http:/ / www.mdpi.com/2071-1050/10/10/3825/ s1, Figure S1: Rarefaction curves of microbial communities based on observed species at a $97 \%$ identify threshold, Table S1: Effects of agricultural management and cultivation type on soil variables and microbial community, Table S2: Significant level of soil variables in explaining the microbial community based on RDA analysis.

Author Contributions: Conceptualization, D.H. and J.L.; Methodology, D.H. and J.L.; Software, J.L. and Y.L.; Formal Analysis, J.L.; Writing-Original Draft Preparation, J.L.; Writing-Review and Editing, D.H. and Y.L.; Visualization, J.L. and Y.L.; Supervision, D.H.; Project Administration, D.H.; Funding Acquisition, D.H.

Funding: This research was funded in part by Shanghai Agriculture Applied Technology Development Program, China (Grant No. T20170304), Agricultural Research System of Shanghai, China (Grant No. 2018-2) and The Municipal Agricultural Commission, China (2017 1-3). Any opinions, findings, conclusions or recommendations expressed in this publication are those of the authors and do not necessarily reflect the view of Ministry of Science and Technology of China or Shanghai Jiao Tong University.

Acknowledgments: We thank Shanghai Personal Biotechnology Co., Ltd., China for their kind assistance with the pyrosequencing experiments.

Conflicts of Interest: The authors declare no conflict of interest.

\section{References}

1. Doran, J.W.; Zeiss, M.R. Soil health and sustainability: Managing the biotic component of soil quality. Appl. Soil Ecol. 2000, 15, 3-11. [CrossRef]

2. Bacon, C.W.; Palencia, E.R.; Hinton, D.M. Abiotic and Biotic Plant Stress-Tolerant and Beneficial Secondary Metabolites Produced by Endophytic Bacillus Species. In Plant Microbes Symbiosis: Applied Facets; Arora, N.K., Ed.; Springer India: Uttar Pradesh, India, 2015; pp. 163-177, ISBN 978-813222068-8.

3. Ding, L.; Su, J.; Sun, G.; Wu, J.; Wei, W. Increased microbial functional diversity under long-term organic and integrated fertilization in a paddy soil. Appl. Microbiol. Biotechnol. 2018, 102, 1969-1982. [CrossRef] [PubMed]

4. Hartmann, M.; Frey, B.; Mayer, J.; Mäder, P.; Widmer, F. Distinct soil microbial diversity under long-term organic and conventional farming. ISME J. 2015, 9, 1177-1194. [CrossRef] [PubMed]

5. Wagg, C.; Bender, S.F.; Widmer, F.; van der Heijden, M.G. Soil biodiversity and soil community composition determine ecosystem multifunctionality. Proc. Natl. Acad. Sci. USA 2014, 111, 5266-5270. [CrossRef] [PubMed]

6. Van Bruggen, A.H.C.; Semenov, A.M.; Van Diepeningen, A.D.; De Vos, O.J.; Blok, W.J. Relation between soil health, wave-like fluctuations in microbial populations, and soil-borne plant disease management. Eur. J. Plant. Pathol. 2006, 115, 105-122. [CrossRef]

7. Degrune, F.; Dufrêne, M.; Colinet, G.; Massart, S.; Taminiau, B.; Bodson, B.; Hiel, M.P.; Daube, G.; Nezer, C.; Vandenbol, M. A novel sub-phylum method discriminates better the impact of crop management on soil microbial community. Agron. Sustain. Dev. 2015, 35, 1157-1166. [CrossRef]

8. Ye, J.; Perez, P.G.; Zhang, R.; Nielsen, S.; Huang, D.; Thomas, T. Effects of different C/N ratios on bacterial compositions and processes in an organically managed soil. Biol. Fertil. Soils 2018, 54, 137-147. [CrossRef]

9. Xiong, W.; Li, Z.; Liu, H.; Xue, C.; Zhang, R.; Wu, H.; Li, R.; Shen, Q. The Effect of Long-Term Continuous Cropping of Black Pepper on Soil Bacterial Communities as Determined by 454 Pyrosequencing. PLoS ONE 2015, 10, e0136946. [CrossRef] [PubMed]

10. Jiménez-Bueno, N.; Valenzuela-Encinas, C.; Marsch, R.; Ortiz-Gutiérrez, D.; Verhulst, N.; Govaerts, B.; Dendooven, L.; Navarro-Noya, Y. Bacterial indicator taxa in soils under different long-term agricultural management. J. Appl. Microbiol. 2016, 120, 921-933. [CrossRef] [PubMed]

11. Bünemann, E.K.; Schwenke, G.D.; Van Zwieten, L. Impact of agricultural inputs on soil organisms-A review. Aust. J. Soil Res. 2006, 44, 379-406. [CrossRef]

12. Tilman, D.; Cassman, K.G.; Matson, P.A.; Naylor, R.; Polasky, S. Agricultural sustainability and intensive production practices. Nature 2002, 418, 671-677. [CrossRef] [PubMed] 
13. Wu, Y.; Xi, X.; Tang, X.; Luo, D.; Gu, B.; Lam, S.K.; Vitousek, P.M.; Chen, D. Policy distortions, farm size, and the overuse of agricultural chemicals in China. Proc. Natl. Acad. Sci. USA 2018, 115, 7010-7015. [CrossRef] [PubMed]

14. Gomiero, T.; Pimentel, D.; Paoletti, M.G. Environmental impact of different agricultural management practices: Conventional vs. Organic agriculture. Crit. Rev. Plant. Sci. 2011, 30, 95-124. [CrossRef]

15. Organic Agriculture Worldwide 2016: Current Statistics. Available online: http:/ / orgprints.org/32677/19/ Willer-2018-global-data-biofach.pdf (accessed on 14 February 2018).

16. Wang, W.; Wang, H.; Feng, Y.; Wang, L.; Xiao, X.; Xi, Y.; Luo, X.; Sun, R.; Ye, X.; Huang, Y.; et al. Consistent responses of the microbial community structure to organic farming along the middle and lower reaches of the Yangtze River. Sci. Rep. 2016, 6, 35046. [CrossRef] [PubMed]

17. Sengupta, A.; Dick, W.A. Bacterial Community Diversity in Soil Under two Tillage Practices as Determined by Pyrosequencing. Microb. Ecol. 2015, 70, 853-859. [CrossRef] [PubMed]

18. Fernandez, A.L.; Sheaffer, C.C.; Wyse, D.L.; Staley, C.; Gould, T.J.; Sadowsky, M.J. Structure of bacterial communities in soil following cover crop and organic fertilizer incorporation. Appl. Microbiol. Biot. 2016, 100, 9331-9341. [CrossRef] [PubMed]

19. Gomez, E.; Ferreras, L.; Toresani, S. Soil bacterial functional diversity as influenced by organic amendment application. Bioresour. Technol. 2006, 97, 1484-1489. [CrossRef] [PubMed]

20. Lupwayi, N.Z.; Larney, F.J.; Blackshaw, R.E.; Kanashiro, D.A.; Pearson, D.C.; Petri, R.M. Pyrosequencing reveals profiles of soil bacterial communities after 12 years of conservation management on irrigated crop rotations. Appl. Soil Ecol. 2017, 121, 65-73. [CrossRef]

21. Gu, Y.; Wang, Y.; Lu, S.; Xiang, Q.; Yu, X.; Zhao, K.; Zou, L.; Chen, Q.; Tu, S.; Zhang, X. Long-term Fertilization Structures Bacterial and Archaeal Communities along Soil Depth Gradient in a Paddy Soil. Front. Microbiol. 2017, 8, 1516. [CrossRef] [PubMed]

22. Bonanomi, G.; De Filippis, F.; Cesarano, G.; La Storia, A.; Ercolini, D.; Scala, F. Organic farming induces changes in soil microbiota that affect agro-ecosystem functions. Soil Biol. Biochem. 2016, 103, 327-336. [CrossRef]

23. Kang, Y.; Chang, Y.C.A.; Choi, H.S.; Gu, M. Current and future status of protected cultivation techniques in Asia. Acta Hortic. 2013, 987, 33-40. [CrossRef]

24. IUSS Working Group WRB. World Reference Base for Soil Resources 2006; World Soil Resources Report; FAO: Rome, Italy, 2010.

25. Ma, B.; Li, X.; Chang, S.X. Capping material type affects rhizosphere bacteria community structure in the cover soil in oil sands reclamation. J. Soil Sediments 2017, 17, 2516-2523. [CrossRef]

26. Caporaso, J.G.; Kuczynski, J.; Stombaugh, J.; Bittinger, K.; Bushman, F.D.; Costello, E.K.; Fierer, N.; Peña, A.G.; Goodrich, J.K.; Gordon, J.I.; et al. QIIME allows analysis of high-throughput community sequencing data. Nat. Methods 2010, 7, 335-336. [CrossRef] [PubMed]

27. Magoč, T.; Salzberg, S.L. Flash: Fast length adjustment of short reads to improve genome assemblies. Bioinformatics 2011, 27, 2957-2963. [CrossRef] [PubMed]

28. Edgar, R.C. Search and clustering orders of magnitude faster than BLAST. Bioinformatics 2010, 26, $2460-2461$. [CrossRef] [PubMed]

29. DeSantis, T.Z.; Hugenholtz, P.; Larsen, N.; Rojas, M.; Brodie, E.L.; Keller, K.; Huber, T.; Dalevi, D.; Hu, P.; Andersen, G.L. Greengenes, a chimera-checked $16 \mathrm{~S}$ rRNA gene database and workbench compatible with ARB. Appl. Environ. Microb. 2006, 72, 5069-5072. [CrossRef] [PubMed]

30. Segata, N.; Izard, J.; Waldron, L.; Gevers, D.; Miropolsky, L.; Garrett, W.S.; Huttenhower, C. Metagenomic biomarker discovery and explanation. Genome Biol. 2011, 12, R60. [CrossRef] [PubMed]

31. Hammer, Ø.; Harper, D.A.T.; Ryan, P.D. Past: Paleontological statistics software package for education and data analysis. Palaeontol. Electron. 2001, 4, 1-9.

32. Whalen, J.K.; Chang, C.; Clayton, G.W.; Carefoot, J.P. Cattle Manure Amendments Can Increase the pH of Acid Soils. Soil Sci. Soc. Am. J. 2000, 64, 962-966. [CrossRef]

33. Ge, T.; Nie, S.A.; Wu, J.; Shen, J.; Xiao, H.A.; Tong, C.; Huang, D.; Hong, Y.; Iwasaki, K. Chemical properties, microbial biomass, and activity differ between soils of organic and conventional horticultural systems under greenhouse and open field management: A case study. J. Soil Sediments 2010, 11, 25-36. [CrossRef]

34. Teng, Y.; Wu, J.; Lu, S.; Wang, Y.; Jiao, X.; Song, L. Soil and soil environmental quality monitoring in China: A review. Environ. Int. 2014, 69, 177-199. [CrossRef] [PubMed] 
35. Hong, C.; Si, Y.; Xing, Y.; Li, Y. Illumina MiSeq sequencing investigation on the contrasting soil bacterial community structures in different iron mining areas. Environ. Sci. Pollut. Res. 2015, 22, 10788-10799. [CrossRef] [PubMed]

36. Hou, D.; Li, F. Complexities surrounding China's soil action plan. Land Degrad. Dev. 2017, 28, $2315-2320$. [CrossRef]

37. Bainard, L.D.; Hamel, C.; Gan, Y. Edaphic properties override the influence of crops on the composition of the soil bacterial community in a semiarid agroecosystem. Appl. Soil Ecol. 2016, 105, 160-168. [CrossRef]

38. Zhang, X.; Johnston, E.R.; Li, L.; Konstantinidis, K.T.; Han, X. Experimental warming reveals positive feedbacks to climate change in the Eurasian Steppe. ISME J. 2017, 11, 885-895. [CrossRef] [PubMed]

39. Wang, X.; Sharp, C.E.; Jones, G.M.; Grasby, S.E.; Brady, A.L.; Dunfield, P.F. Stable-Isotope probing identifies uncultured planctomycetes as primary degraders of a complex heteropolysaccharide in soil. Appl. Environ. Microb. 2015, 81, 4607-4615. [CrossRef] [PubMed]

40. Wieczorek, A.; Hetz, S.; Kolb, S. Microbial responses to chitin and chitosan in oxic and anoxic agricultural soil slurries. Biogeosciences 2014, 11, 3339-3352. [CrossRef]

41. Chua, J.P.S.; Orlovich, D.A.; Summerfield, T.C. Cyanobacteria in New Zealand indigenous grasslands. N. Z. J. Bot. 2014, 52, 100-115. [CrossRef]

42. Castellano-Hinojosa, A.; Correa-Galeote, D.; Palau, J.; Bedmar, E.J. Isolation of $\mathrm{N}_{2}$-fixing rhizobacteria from Lolium perenne and evaluating their plant growth promoting traits. J. Basic Microbiol. 2016, 56, 85-91. [CrossRef] [PubMed]

43. Jiang, Y.; Li, Q.; Chen, X.; Jiang, C. Isolation and Cultivation Methods of Actinobacteria. In Actinobacteria-Basics and Biotechnological Applications; Dhanasekaran, D., Ed.; InTech: Rijeka, Croatia, 2016; pp. 39-57.

44. Abazari, M.; Zarrini, G.; Rasooli, I. Antimicrobial potentials of Leptolyngbya sp. and its synergistic effects with antibiotics. Jundishapur J. Microb. 2013, 6, 1-6.

45. Ye, J.; Zhang, R.; Nielsen, S.; Joseph, S.D.; Huang, D.; Thomas, T. A combination of biochar-mineral complexes and compost improves soil bacterial processes, soil quality, and plant properties. Front. Microbiol. 2016, 7 , 372. [CrossRef] [PubMed]

46. Zhang, Y.; Lu, Z.; Liu, S.; Yang, Y.; He, Z.; Ren, Z.; Zhou, J.; Li, D. Geochip-based analysis of microbial communities in alpine meadow soils in the Qinghai-Tibetan plateau. BMC Microbiol. 2013, 13, 72. [CrossRef] [PubMed]

47. Schellenberger, S.; Kolb, S.; Drake, H. Metabolic responses of novel cellulolytic and saccharolytic agricultural soil Bacteria to oxygen. Environ. Microbiol. 2010, 12, 845-861. [CrossRef] [PubMed]

48. Schwarz, W. The cellulosome and cellulose degradation by anaerobic bacteria. Appl. Microbiol. Biot. 2001, 56, 634-649. [CrossRef]

49. Horel, A.; Mortazavi, B.; Sobecky, P.A. Input of organic matter enhances degradation of weathered diesel fuel in sub-tropical sediments. Sci. Total Environ. 2015, 533, 82-90. [CrossRef] [PubMed]

50. Cappelletti, M.; Ghezzi, D.; Zannoni, D.; Capaccioni, B.; Fedi, S. Diversity of Methane-Oxidizing Bacteria in Soils from "Hot Lands of Medolla" (Italy) Featured by Anomalous High-Temperatures and Biogenic $\mathrm{CO}_{2}$ Emission. Microbes Environ. 2016, 31, 369-377. [CrossRef] [PubMed]

51. Rosenzweig, N.; Bradeen, J.; Tu, Z.; McKay, S.; Kinkel, L. Rhizosphere bacterial communities associated with long-lived perennial prairie plants vary in diversity, composition, and structure. Can. J. Microbiol. 2013, 59, 494-502. [CrossRef] [PubMed]

52. Kerou, M.; Offre, P.; Valledor, L.; Abby, S.; Melcher, M.; Nagler, M.; Weckwerth, W.; Schleper, C. Proteomics and comparative genomics of Nitrososphaera viennensis reveal the core genome and adaptations of archaeal ammonia oxidizers. Proc. Natl. Acad. Sci. USA 2016, 113, E7937-E7946. [CrossRef] [PubMed]

53. Wang, X.; Han, C.; Zhang, J.; Huang, Q.; Deng, H.; Deng, Y.; Zhong, W. Long-term fertilization effects on active ammonia oxidizers in an acidic upland soil in China. Soil Biol. Biochem. 2015, 84, 28-37. [CrossRef]

54. Zhang, Z.Y.; Gao, X.H.; Zhang, Y.J.; Jia, M.; Lu, X.J.; Ma, Y.C.; Tian, F.; Xie, Q.; Tang, S.K. Skermanella rubra sp. nov. a bacterium isolated from the desert of Xinjiang, China. Antonie Van Leeuwenhoek 2015, 108, 627-632. [CrossRef] [PubMed]

55. Luo, G.; Shi, Z.; Wang, H.; Wang, G. Skermanella stibiiresistens sp. nov. a highly antimony-resistant bacterium isolated from coal-mining soil, and emended description of the genus Skermanella. Int. J. Syst. Evol. Microbiol. 2012, 62, 1271-1276. [CrossRef] [PubMed] 
56. Li, R.; Khafipour, E.; Krause, D.O.; Entz, M.H.; de Kievit, T.R.; Fernando, W.G.D. Pyrosequencing Reveals the Influence of Organic and Conventional Farming Systems on Bacterial Communities. PLoS ONE 2012, 7, e51897. [CrossRef] [PubMed]

57. Wu, W.; Wu, J.; Liu, X.; Chen, X.; Wu, Y.; Yu, S. Inorganic phosphorus fertilizer ameliorates maize growth by reducing metal uptake, improving soil enzyme activity and microbial community structure. Ecotoxicol. Environ. Saf. 2017, 143, 322-329. [CrossRef] [PubMed]

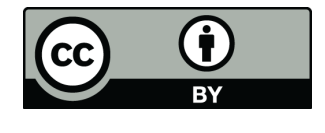

(C) 2018 by the authors. Licensee MDPI, Basel, Switzerland. This article is an open access article distributed under the terms and conditions of the Creative Commons Attribution (CC BY) license (http:/ / creativecommons.org/licenses/by/4.0/). 